\title{
Electrical Power Transmission and Energy Management System
}

\author{
SUBIR SEN $^{1 *}$ and S C SRIVASTAVA ${ }^{2}$ \\ ${ }^{1}$ Smart Grid Division, Power Grid Corporation of India Limited, Gurgaon, India \\ ${ }^{2}$ Department of Electrical Engineering, Indian Institute of Technology, Kanpur, India
}

(Received on 30 May 2014; Accepted on 19 July 2015)

\begin{abstract}
Electrical power transmission system forms an important part of the electricity network required to transfer bulk amount of power produced at remotely located generating stations to the load centres. In most of the countries, including India, the electricity sector has a vast interconnected system of generation, transmission and distribution network, which requires modern computer-aided operation and control system. Such a system is called 'Energy Management System (EMS)', conventionally based on Supervisory Control and Data Acquisition (SCADA) features. With the recent development of dielectric as well as conducting materials, power electronic devices, information technology and automation system, a new class of transmission and control equipment is being used and the energy management system is also being modernized. Recent blackouts in India and other countries have prompted the use of Wide Area Monitoring Control and Protection System (WAMCPS) based on synchrophasor technology for real time monitoring of dynamic states and security of the system. This paper describes the present status and future developments in the electrical power transmission, energy management system, and emerging technologies, specifically in the Indian context.
\end{abstract}

Keywords: Power Transmission; Energy Management System; Indian Scenario; New Technology

\section{Role of Power Transmission in the Electricity Sector}

Electric power has become the most essential commodity and vital input for the growth of any economy. It facilitates development across various sectors such as manufacturing, agriculture, commercial, education, railways, etc., to achieve economic growth. Accelerated economic growth of the country, along with globalization and liberalization, will result in high increase in power demand in future. To sustain the pace of growth, overall expansion of the electricity sector including generation, transmission and distribution, with adequate reliability, is required.

Indian power sector is one of the most diversified sectors, consisting of a variety of generation resources including conventional/non-conventional sources, to meet the demand. Utilizing the availability of these diverse resources, the country has been continuously planning the generation capacity addition. As of March 2015, the total installed generation capacity in the country is about 267.6 GW (CEA Report,March 2015), consisting of $164.6 \mathrm{GW}$ of coal-based, 23.0 $\mathrm{GW}$ of gas-based, 1.2 GW of diesel-based, 5.8 GW of nuclear, $41.3 \mathrm{GW}$ of large hydro and $31.7 \mathrm{GW}$ of renewable energy sources.

The generation mix of conventional sources is $87 \%$, while the renewables contribute about $13 \%$ of the non-conventional sources. Coal still dominates $(61 \%)$ as fuel resource in the overall electricity generation portfolio. The country's present peak power demand is about $148.2 \mathrm{GW}$, whereas energy requirement is about 1067 billion units (BU). However, there is still a shortage of about $4.7 \%$ and $3.6 \%$ of the peak demand and energy requirement, respectively.

Electricity demand in the Indian power system is expected to increase to more than $300 \mathrm{GW}$ by the

*Author for Correspondence: E-mail: subir@powergridindia.com, Tel: +91-512-2597625 
end of the $12^{\text {th }}$ five year plan (2016-17). Towards this demand, the Government of India has an ambitious plan to add about $88 \mathrm{GW}$ during the $12^{\text {th }}$ plan through conventional resources. In addition, 30-40 GW capacity is also envisaged to be added through renewable/non-conventional sources during the $12^{\text {th }}$ plan period.

The natural resources of electricity generation in India are unevenly dispersed and concentrated in a few pockets, while load centres are dispersed in all the regions. In this scenario, to cater to the bulk demand at the load centres, either natural fuel such as coal/gas needs to be transported over a long distance to run the power plants near the load centers or the electrical power has to be transmitted over a long distance through transmission lines. It has been found that the transmission of power from pithead coal-based power plants and remote located hydro plants to the load centres is economical and technically viable from the energy management perspective through High Voltage AC (HVAC) or High Voltage DC (HVDC) transmission networks.

Due to large demography, demand varies over the day/week/month as well as on seasonal/regional basis. To cater to such a variable demand pattern, the generation portfolio should have a mix of various fuel technologies. Therefore, the transmission system needs to be strengthened to transfer power from generating plants having a mix of fuels across regions and states as well as to cater to the demand under all operating conditions. In an open electricity market, wherein long-term, medium-term and short-term contracts are taking place, the price of electricity depends upon the supply-demand balance. The consumer aspires for affordable and reliable power while the supplier's concern is on maximizing the profit. The transmission network plays a key role in managing/wheeling electricity from one part to other part of the network to meet the transactions, while ensuring reliability and security of supply.

Thus, the transmission plays a vital role in the overall development of the power system. It is the central link in the entire electricity supply delivery chain interconnecting sources to the distantly located load centres. A robust and reliable transmission network has to be planned to ensure supply in a secure manner at reasonable cost (Gonen, 2009). It also offers the sellers and buyers of electric power a choice and, thereby, facilitates development of an open electricity market.

\section{Energy Management System}

In the present day large interconnected power systems, the demand forpower is always increasing, which requires expansion of the transmission networks. However, addition of new transmission lines is not always feasible due to economical, environmental and right of way constraints. This leads to the stressed operation of the system and calls for its continuous monitoring as well as assessment of security and stability. Increased vulnerability of the modern power systems to blackouts under contingencies, demands for the development of monitoring and assessment tools. Further, the operating conditions and the dynamics of the system change frequently with the changes in loading conditions. To understand and predict the operating conditions and to monitor the vital parameters of the system closely, automation, control and application software are required for quick response to the operating conditions as well as to perform the forecasting and postmortem analysis.

Since the last 4-5 decades, for the operation and control of the power system, a combination of computer and communication hardware along with software application suites, is being utilized by the power system utilities, which is commonly called as the 'Energy Management System' (EMS) (Talukdar and $\mathrm{Wu}, 1981$ ). This system has been used in most of the power systems across the globe mainly at generation and transmission levels, which acquires measured quantities, such as Root Mean Square (RMS) values of the bus voltages, branch currents and power flows at a scan rate of 2-10 s. To scan the measured quantities, Remote Terminal Units (RTUs) are installed near the substations or generating stations to receive the analogue measurement and digital status signals from the field equipment, which are to be monitored remotely. The RTUs are equipped with 
analogue/digital measurement devices, a suitable Analogue to Digital (A/D) converter, and communication channel to send and receive the data to control centres and also the control commands to the field equipment. Conventionally, telemetry links have been used for data communication, which are being replaced by fibre optic links.

In the past, the important application of the EMS has been the Supervisory Control and Data Acquisition (SCADA). The SCADA system spools the required power system measured quantities from the RTUs, filters and analyses it for various applications. The filtered data is further used by other software applications such as state estimator, security enhancement, contingency analysis, and short circuit analysis. A typical architecture of the EMS is shown in Fig. 1.

Important components of the EMS applications' suite includes SCADA application, communication and control applications, network management, state estimation, contingency analysis, economic load dispatch or optimal power flow, Automatic Generation Control (AGC), security assessment, fault detection, isolation and restoration, dispatcher training simulator, and various offline tools such as load flow, playback, historian, etc.

The dispatcher training simulator is the tool used to provide training on EMS applications to the operators responsible for the operation and control of the power system networks. In large electricity networks such as those in India, hierarchical architecture of EMS has evolved, having control centres at national level, five at regional level and one in each of the states known as National Load Dispatch Centre (NLDC), Regional Load Dispatch Centre (RLDC) and State Load Dispatch Centre (SLDC). The required application software for functioning of electricity markets is also being embedded at the control centres, to be operated by the system operators (SOs). The EMS is continuously being modernized (Wu et al., 2005) utilizing the new technologies of computing and communication. Of late, the distribution systems are also being provided with SCADA systems, commonly known as Distribution Management System (DMS) or Distribution Automation System (DAS), where application functions are different, such as load estimation and forecasting, Volt/Var management, network reconfiguration, automatic billing, equipment health monitoring, etc.

\section{Present Status of Transmission Network}

\section{Existing Transmission Network in India}

Electricity is a concurrent subject in India. Both the central and the state governments are responsible for the development of this sector. There are number of central generation utilities such as National Thermal Power Corporation (NTPC), National Hydro Power Corporation (NHPC), Tehri Hydro Dam Corporation (THDC), North Eastern Electric Power Corporation Ltd. (NEEPCO), Satluj Jal Vidyut Nigam Limited (SJVNL), Neyveli Lignite Corporation Limited (NLC), etc. Power Grid Corporation of India Limited (POWERGRID) is the Central Transmission Utility

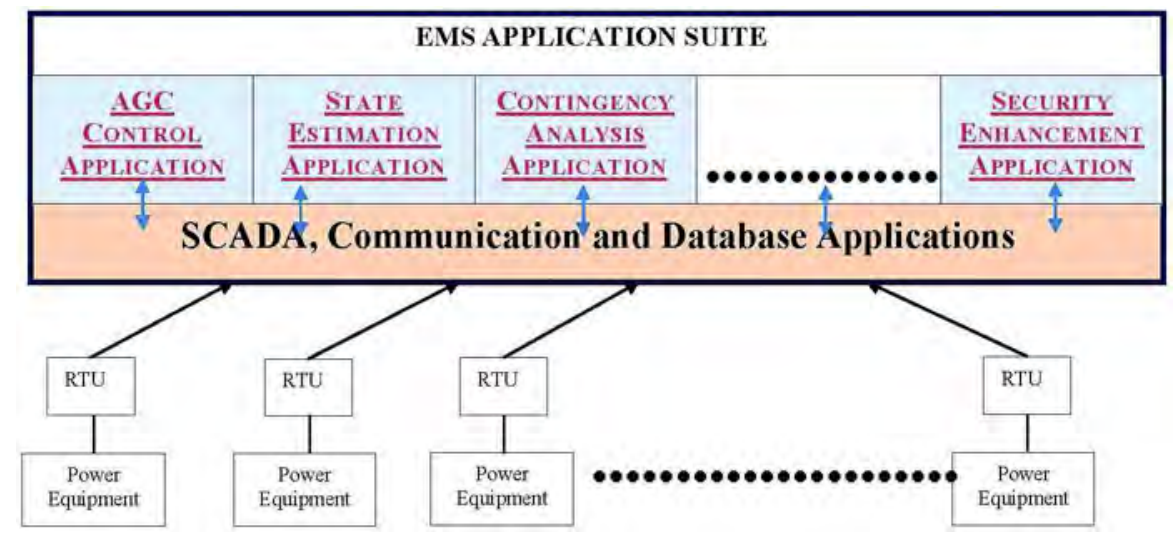

Fig. 1: Typical Energy Management System Architecture 
(CTU). At the state level, separate Generation company (Genco) and Transmission company (Transco) have been formed. Distribution of power is under the purview of the respective state utilities. Central Electricity Regulatory Commission (CERC) is the regulatory authority at the central level with State Electricity Regulatory Commissions (SERCs) at the state level. For the sake of better coordination between the state utilities, the country has been demarcated into five electrical regions, namely Northern Region (NR), Southern Region (SR), Eastern Region (ER), Western Region (WR) and North Eastern Region (NER), as shown in Fig. 2.

Over decades, a robust inter-state/intra-state and inter-regional transmission system has been evolved in the country, which facilitates widespread reach of power over the vast areas. At the time of independence, maximum voltage level of transmission was at $132 \mathrm{kV}$, which was subsequently increased to $220 \mathrm{kV}$ in 1960 and 400kV AC in 1977. To reduce the Right of Way (ROW) requirement for transmission lines along with large quantum of power transfer requirement and to overcome constraints on availability of land for substations, $765 \mathrm{kV}$ AC transmission voltage and Gas Insulated Substations

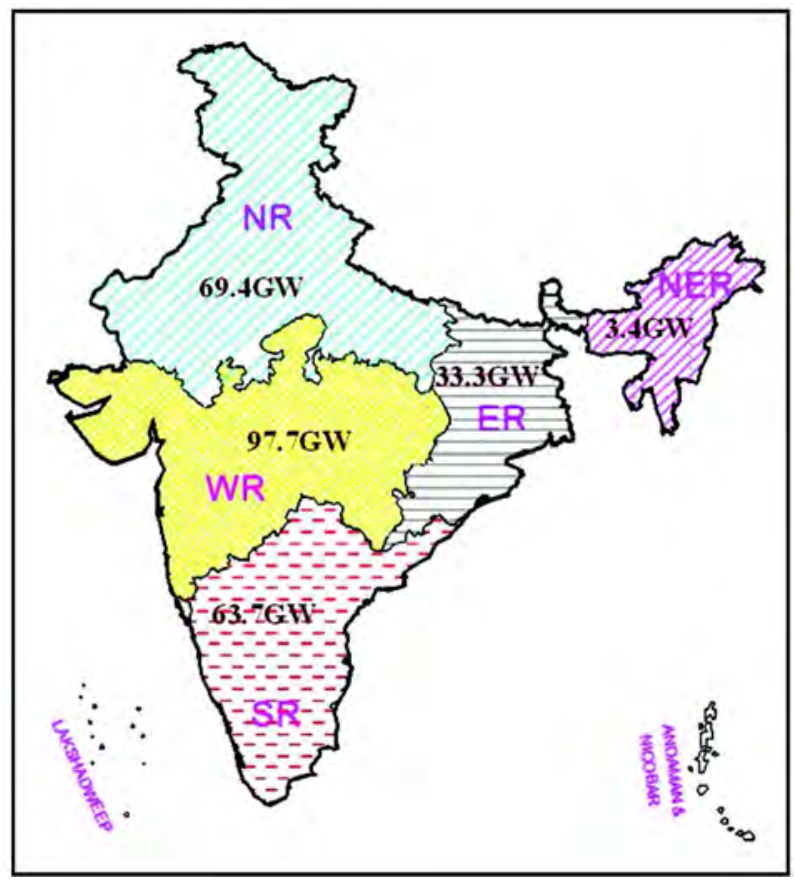

Fig. 2: Five Electrical Regions of India (CEA Report, March 2015)
(GIS) are now being increasingly used. In addition, the long distance $\pm 500 \mathrm{kV}$ HVDC and back-to-back systems are also in place.

Both inter-state as well as intra-state transmission networks have seen rapid growth over the last two decades and have established a robust system mainly comprising $400 \mathrm{kV} / 765 \mathrm{kV}$ AC and $\pm 500 \mathrm{kV}$ HVDC as part of the national grid to facilitate widespread reach of power across the country. Till 2013, the Indian power system comprised two grids at national level viz., NEW grid (capacity $169 \mathrm{GW}$ ), which synchronously interconnected NR, ER, WR and NER grids, and Southern Grid (56 GW), with over $4000 \mathrm{MW}$ asynchronous interconnection through HVDC lines between these two grids. In a recent major development, the $765 \mathrm{kV}$ single circuit SolapurRaichur transmission line was synchronized on 31 December 2013 midnight and it connected the NEW grid to the southern power grid. With the synchronization of the Solapur-Raichur line, the southern states are set to benefit by way of increased power import as it would obtain power from the power-surplus regions and states.

The backbone transmission system in India mainly occurs through $400 \mathrm{kV}$ and $765 \mathrm{kV}$ AC network with approximately $1,54,593$ circuit $\mathrm{km}$ (ckm) of line length and 3,13,922 MVA transformation capacity. These are supported by about $1,49,412 \mathrm{ckm}$ of $220 \mathrm{kV}$ transmission network with 2,68,678 MVA transformation capacity. In addition, $\pm 500 \mathrm{kV}, 1500$ / 2500MW long distance HVDC (4 nos.) systems traverse about 9500 circuit $\mathrm{km}$ with $13,500 \mathrm{MW}$ power transfer capacity including 4 nos. HVDC back-toback interconnecting links. Details of existing transmission network $(220 \mathrm{kV} \&$ above) in circuit kilometers owned by state/private/central sectors are provided in Table1 (CEA Report, March 2015).

For the transmission infrastructure at the central level or Inter State Transmission System (ISTS), POWERGRID is responsible for its development as well as Operation and Maintenance (O\&M). It owns and operates about 1,15,637ckm of transmission line at $400 \mathrm{kV} / 765 \mathrm{kV}$ level, 192 nos. Extra High Voltage (EHV) substations and HVDC stations with about 2,31,709 MVA transformation capacity 
Table 1: Present Status of $220 \mathrm{kV}$ and above Voltage Transmission System in India (CEA Report, 2015) (as on March 2015)

\begin{tabular}{lrrrrr}
\hline S.No. Line/station & $\begin{array}{r}\text { Central } \\
\text { sector }\end{array}$ & $\begin{array}{r}\text { State } \\
\text { sector }\end{array}$ & JV/Pvt & Total \\
\hline \multicolumn{5}{l}{ Transmission line (ckm) Voltage Level } \\
1 & $765 \mathrm{kV}$ & 15810 & 840 & 1994 & 18644 \\
2 & $400 \mathrm{kV}$ & 82786 & 40394 & 12769 & 135949 \\
3 & $220 \mathrm{kV}$ & 10582 & 137932 & 898 & 149412 \\
4 & $\pm 500 \mathrm{kV}$ HVDC & 5948 & 1504 & 1980 & 9432 \\
Substation (MVA) & & & & \\
1 & $765 \mathrm{kV}$ & 100500 & 9000 & 12000 & 121500 \\
2 & $400 \mathrm{kV}$ & 99175 & 92617 & 630 & 192422 \\
3 & $220 \mathrm{kV}$ & 8176 & 258935 & 1567 & 268678 \\
4 & $\pm 500 \mathrm{kV}$ HVDC & 9500 & 1500 & 2500 & 13500 \\
\hline
\end{tabular}

(POWERGRID website). It has a plan to develop additional about $66,000 \mathrm{ckm}$ transmission line mainly at $400 \mathrm{kV}$ and $765 \mathrm{kV}$ levels and more than 90 substations with about 1,50,000 MVA transformation capacity during $12^{\text {th }}$ plan.(http://www.cea.nic.in/ more_upload/conclave/23.pdf)

All the five regions are interconnected through the National Grid comprising the hybrid AC/HVDC system through the ISTS system. Recognizing the need for development of a strong National Grid, thrust was given to enhance the interregional capacity in a phased manner. The total inter-regional transmission capacity at present is about $46,450 \mathrm{MW}$.

\section{Transmission Losses}

Although the overall Transmission and Distribution (T\&D) losses in India are quite high, about 26\% (CEA report, March 2015), the transmission losses are in the range of $3.5 \%$ to $4 \%$, which is comparable with other international utilities. The losses are mainly technical in nature, which are intrinsic to power transmission systems and depend on the type of conductors used, length of transmission lines, voltage profile, loading levels on the equipment, etc. Broadly, technical losses are categorized (Navani et al., 2012) as (a) resistive losses inherent in all conductors because of the finite electrical resistance of conductors, (b) dielectric losses resulting from the heating effect in the dielectric material used between conductors or conductor to ground, and (c) induction and radiation losses that are produced by the electromagnetic fields surrounding conductors.

In order to maintain transmission losses within limits, new transmission technologies have been introduced/under implementation in the country (CEA NEP report, 2012), including $\pm 800 \mathrm{kV}, 6000 \mathrm{MW}$ HVDC system, $765 \mathrm{kV} / 1200 \mathrm{kV}$ UHVAC, dynamic reactive compensation through the Flexible AC Transmission System (FACTS) in the grid.

Majority of the T\&D loss occurs in the distribution sector, which contains both technical and commercial loss. Commercial loss occurs due to poor metering and return of revenue; whereas, higher technical losses are attributed to the unplanned growth of distribution sector, resulting in very long lines, lack of adequate reactive power support, lack of information about loading condition and poor health of equipment leading to their frequent failure. Certain measures to reduce the losses are re-conductoring of lines and reconfiguration of the distribution system, optimal capacitor installation, substation and feeder automation, with features of system and equipment health monitoring, load and demand side management, etc.

\section{Future Requirement, Issues and Challenges in Transmission}

\section{Generation Capacity Addition Program}

India has an installed capacity of $268 \mathrm{GW}$ as of March 2015 , the world's fifth largest, yet faces an energy deficit of $3.6 \%$ and a peak load deficit of about $4.7 \%$. The average per capita consumption of electricity is a meager $957 \mathrm{kWh}$ (2013-14), compared to the world average of about 2,500 $\mathrm{kWh}$. The other comparable countries in the BRICS group (Brazil, Russia, China, and South African nations) have significantly higher per capita consumption than India. The average percapita consumption in India has grown steadily at $4.7 \%$ CAGR annually over the last 10 years. 
As per the estimates, peak demand in the country by 2021-22 and 2031-32 may increase to about 323 GW and $592 \mathrm{GW}$, respectively, and the corresponding installed capacity requirement shall be about $425 \mathrm{GW}$ and $778 \mathrm{GW}$, respectively (IEP report, 2006). Progressively, the generation capacity requirement by 2031-32 is projected as shown in Fig. 3.

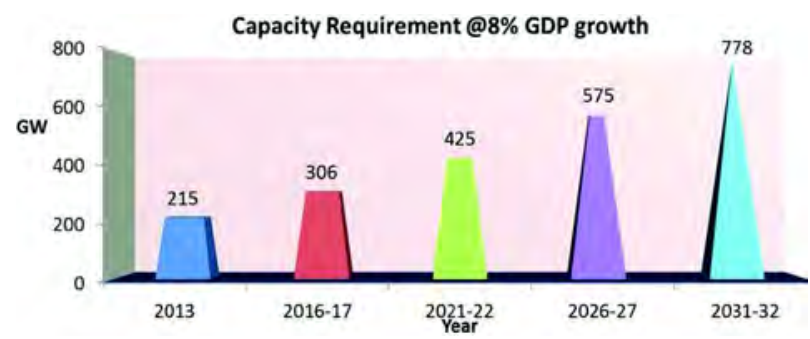

Fig. 3: Estimated Generation Capacity Addition (IEP Report, 2006)

\section{Energy Resource Locations}

The natural resources for electricity generation in India are unevenly dispersed and concentrated in a few pockets. Hydro resources are located in the Himalayan foothills and in the north-eastern region. Coal reserves are concentrated in Jharkhand, Orissa, West Bengal, Chhattisgarh, and parts of Madhya Pradesh; whereas, lignite is located in Tamil Nadu and Gujarat. North Eastern Region (NER) and Bhutan have vast untapped hydro potential estimated to be about 50,000 MW in NER and about 15,000 MW in Bhutan. India has some of the largest reserves of coal in the world (approx. 267 billion tonnes). Coal reserves are mainly located in Orissa, Chhattisgarh, Jharkhand, Maharashtra (Nagpur \& Chandrpur), West Bengal (Ranijang), Andhra Pradesh (Khammam), and Tamil Nadu (Neyveli). Energy resource map of India is shown in Fig. 4.

The distribution of energy resources and load centres are extremely unbalanced. The load centres are scattered at far-off places away from resourcerich areas located in the northern part of India. Recent government initiatives for establishment of special economic zones have also given rise to new potential load centres. Projects are proposed to be located mostly at pit head/resource areas, with each location having capacities in the range of 5,000-10,000 MW.

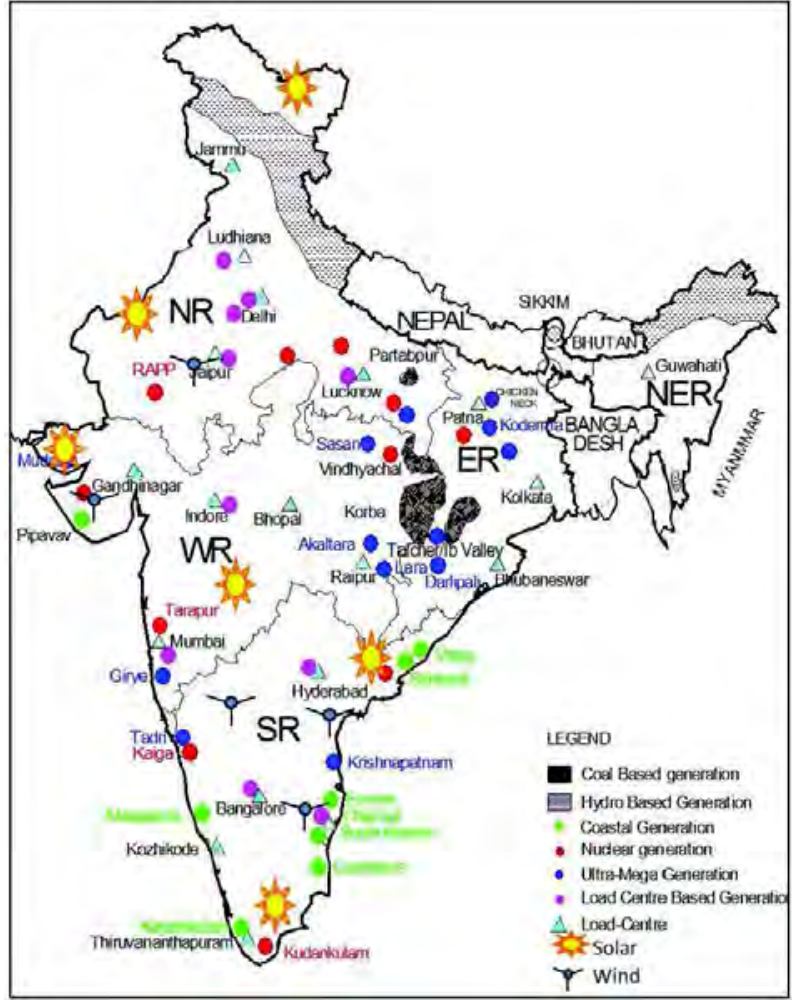

Fig. 4: Energy Resource Map of India (POWERGRID Website http://www.powergridindia.com)

\section{Issues and Challenges in Transmission}

Of late, transmission sector is facing new challenges which have arisen out of rapid growth of the electricity sector coupled with increased requirement of power transfer. Pocketed generation resources and wide spread load centers across the country, coupled with ROWproblems, necessitate development of high capacity transmission corridors. However, major concerns towards planning of such corridors include right-of-way and protection of flora and fauna, Rehabilitation \& Resettlement (R\&R), flexibility to enhance the transfer capacity in view of uncertainty of generation projects, implementation in different phases, optimization of transmission cost and losses, non-discriminatory open access to facilitate electricity market, cable manufacturers' to research \& develop cables with new type of insulating and conducting materials, integration of large scale renewable energy sources with the grid in an optimal manner, creation of reliable repairing facilities \& development of indigenous manufacturing capacity, skilled manpower 
for implementation of huge network, and new challenges in operation and maintenance.

In the current electricity supply regime, various uncertainties are associated with the transmission system development process. Some of the key uncertainties pushing a paradigm shift in transmission system planning include uncertainties in development of generation project, no firm beneficiaries at the development stage of generation project due to introduction of competitively bid generation tariff, and recovery of investment towards transmission development.

\section{Transmission Plan}

There has been a consistent increase in the transmission network and transformation capacity in India. This increase is in consonance with the increase in generation and demand of electricity in the country.

Considering the generation capacity addition plan for the $12^{\text {th }}$ plan period and commensurate power transfer requirement, transmission line additions of about 1,00,000 ckm, HVDC terminal capacity of 13,000 MW and AC transformation capacity of 2,70,000 MVA has been planned for the $12^{\text {th }}$ Plan.

Table 2: Projected Transmission Network Growth $\left(1^{\text {th }}\right.$ Plan Report, 2012)

\begin{tabular}{|c|c|c|c|c|}
\hline \multicolumn{2}{|c|}{$\begin{array}{l}\text { S.No. Line/station } \\
\text { Total }\end{array}$} & $\begin{array}{l}\text { At the end } \\
\text { of } 11^{\text {th }} \text { plan }\end{array}$ & $\begin{array}{r}\text { Envisaged } \\
\text { addition } \\
\text { during } 12^{\text {th }} \\
\text { plan }\end{array}$ & $\begin{array}{r}\text { Expected by } \\
\text { end of } 12^{\text {th }} \\
\text { plan } \\
\text { (cumulative) }\end{array}$ \\
\hline \multicolumn{3}{|c|}{ Transmission line (ckm) } & \multicolumn{2}{|l|}{ Voltage Level } \\
\hline 1 & $765 \mathrm{kV}$ & 5730 & 27000 & 32730 \\
\hline 2 & $400 \mathrm{kV}$ & 113367 & 38000 & 151367 \\
\hline 3 & $220 \mathrm{kV}$ & 140164 & 35000 & 175164 \\
\hline 4 & HVDC & 9432 & 7440 & 16872 \\
\hline \multicolumn{5}{|c|}{ Substation (MVA) } \\
\hline 1 & $765 \mathrm{kV}$ & 25000 & 149000 & 174000 \\
\hline 2 & $400 \mathrm{kV}$ & 151027 & 45000 & 196027 \\
\hline 3 & $220 \mathrm{kV}$ & 223774 & 76000 & 299774 \\
\hline 4 & HVDC (MW) & 11200 & 12750 & 22500 \\
\hline
\end{tabular}

Table 2 shows the transmission infrastructure addition envisaged in the $12^{\text {th }}$ plan.

The inter-regional transmission capacity of allIndia grid level is about 46,450 MW which shall be enhanced to more than 66,000 MW by 2017 and $1,26,650$ MW by 2021-22. Fig. 5 shows the growth in interregional capacity by $2021-22$ (end of $13^{\text {th }}$ plan).The generation projects are mainly concentrated in small pockets in areas such as pit-heads in Orissa, Chhattisgarh, Jharkhand or coastal sites with port facilities in Andhra Pradesh, Tamil Nadu or hydro sites in Sikkim, etc. To address the ROW issue as well as transfer of bulk power over long distances and keeping in view the long-term power transfer requirement, the development of High Capacity Transmission Corridors (HCTC) comprises $765 \mathrm{kV}$ AC and $\pm 800 \mathrm{kV}, 6000$ MW HVDC multi-terminal line, which is being laid starting from NER to NR and other regions.

These transmission highways would facilitate transfer of power from remotely located bulk power generation projects to major load centres. A schematic diagram of 11 such planned HCTCs is shown in Fig. 6.

Based on the progress and development of generation projects and transmission systems during the $12^{\text {th }}$ Plan, only a broad assessment of transmission capacity addition for the $13^{\text {th }}$ plan can be made considering probable load growth and indicative generation capacity addition scenarios for the $13^{\text {th }}$ plan.

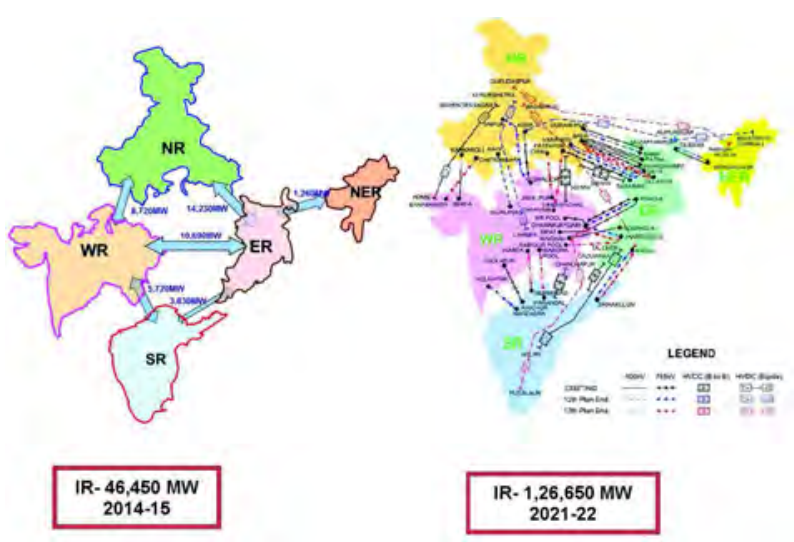

Fig. 5: Growth in Interregional Capacity (CEA Transmission Plan Report, 2014) 


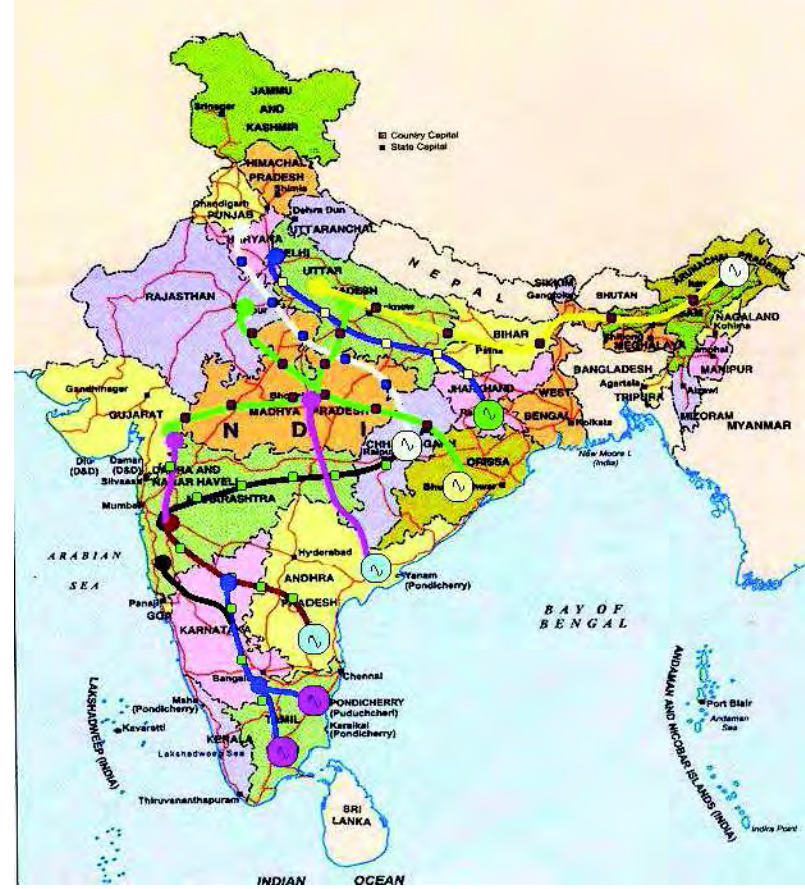

Fig. 6: High Capacity Transmission Corridor (NPTI Website, http://www.npti.in)

Accordingly, during the $13^{\text {th }}$ plan period, transmission capacity addition of about $1,30,000 \mathrm{~km}$ and 3,00,000 MVA substation transformation capacity have been envisaged.

As part of the evolution of "Green Energy Corridors", POWERGRID has identified transmission requirement both at inter-state and intrastate levels for grid integration of envisaged renewable capacity addition of the $12^{\text {th }}$ plan (Green Energy Corridor Report, 2012). To address the intermittency and variability characteristics of renewable generation, other control infrastructures such as forecasting of renewable generation and demand, real time measurement/monitoring through synchrophasor technology, flexible generation, ancillary reserves, demand-side and demand response management and energy storage, establishment of Renewable Energy Management Centres (REMC) are also identified.

\section{New Technologies in Power Transmission}

Transmission sector has consistently adopted relevant global trends to support sustainable growth in the Indian power sector. The increasing maturity of the sector is evidenced by adoption and indigenization of new technologies across the power transmission sector in general and power sector, in particular.

Transmission utilities are focusing on innovation for development of new transmission technologies and seamless integration in the Indian context. In order to meet the growing power transfer requirement with increased inter-state power transfer requirement and addressing the associated challenges, a two-pronged approach has been adopted on the technology front. In the first approach, capacity and reliability of existing transmission infrastructure is enhanced using new technologies. In this direction, many emerging technologies are already integrated into the transmission system such as FACTS devices (Hingorani and Gyugyi, 2000), e.g. Static VAR compensator (SVC), Thyristor Controlled Series Capacitors (TCSC), Fixed Series Compensation (FSC), reconductoring of transmission lines with higher capacity conductors, etc.

In the second approach, new systems are being designed keeping the long-term perspective utilizing the latest state-of-the-art technologies. In this direction, new technologies such as high capacity $765 \mathrm{kV}$ transmission system $(765 \mathrm{kV}$ double circuit lines), $\pm 800 \mathrm{kV} 6000 \mathrm{MW}$ HVDC and $1200 \mathrm{kV}$ UHV AC technologies, gas insulated substation (compaction), substation automation, compact towers, High Temperature Low Sag (HTLS) conductor, etc. are introduced in addition to existing technical developments.

The country is also establishing the world's highest transmission voltage level of $1200 \mathrm{kV} \mathrm{UHV-}$ AC with the establishment of a national test station at Binain Madhya Pradesh in 2012. This technology has been fully developed indigenously with the collaborative effort of 35 Indian manufacturers under Public Private Partnership (PPP).

Further, the country's first $\pm 800 \mathrm{kV}$ HVDC multi-terminal transmission system for bulk power transmission from Biswanath Chariali, in the northeastern region to Agra in the northern region, about $2000 \mathrm{~km}$, is also under implementation and upon completion, this system will be among the world's 
longest $\pm 800 \mathrm{kV}$ HVDC multi-terminal system with power transfer capacity of 6000-8000MW.

To facilitate safe, secure and reliable operation of the large grid so as to avoid frequent outages through openings of lines due to over voltage, which was otherwise found to weaken the grid under emergency situation (Report on grid disturbance in July 2012 in India), and also providing voltage support during various operating conditions under steady state and dynamic conditions, installation of suitable static and dynamic reactive compensation are essential. Static compensation is provided in the form of a bus/ line reactor, while dynamic compensation is achieved through SVC/STATCOMs. In this direction, 16 SVC/ STATCOMs are now planned at various strategic locations among all regions to meet the dynamic reactive requirement.

With scarce land availability, there is a growing need for reduction of land use for setting up of transmission systems, particularly in metros, hilly and other urban areas. Gas Insulated Substations (GIS), which require less space (about $80 \%$ reduction), i.e. 5-6 acres as compared to conventional substation which generally requires an area of 30-40 acres. A number of $400 \mathrm{kV}$ GIS substations are established and many more are under implementation including those of $765 \mathrm{kV}$ level. In special areas, compact towers such as delta configuration, narrow-based tower, etc., which reduce the space occupied by the tower base, are being used. In this direction, $765 \mathrm{kV}$ tower with delta configuration and $400 \mathrm{kV}$ pole structure are quite useful and are being adopted.

To meet various emerging requirements such as achieving controllability/flexibility at grid level, integration of large scale renewable necessitates adoption of other state-of-the-art emerging technologies such as Voltage Source Converter (VSC) based HVDC technology, energy storage technologies, etc.

To improve the efficiency of overall grid management in open electricity market regime, enhanced situational awareness, control at the control centres, and implementation of synchrophasor technology have been planned for wide area monitoring of state and central grids through placement of Phasor Measurement Units (PMUs) at all HVDCs, $400 \mathrm{kV}$ and above substations/generating stations, PDCs (Phasor Data Concentrators) at strategic locations, along with required analytics based on PMU measurements such as the Unified Real Time Dynamic State Measurement(URTDSM) system.

\section{Smart Transmission Grid Using Synchro-phasor Technology}

The existing SCADA/EMS, as shown in Fig. 7, utilizes the Remote Terminal Units (RTUs) for measuring the voltage and current magnitudes. It also measures power flows in the lines. Typically, the RTUs provide measurements at a refresh rate of 2-10 s, which are time skewed. Preprocessing of the data, collected from the RTUs, is carried out at the control centre, which includes the processing of bad data, and carrying out the state estimation. These functions collectively result in estimation of the states, at a typical time interval of 5-10 min. Hence, the SCADA/EMS is suitable for monitoring the system under the steady state, but is not suitable for observing the system under transients or dynamic conditions.

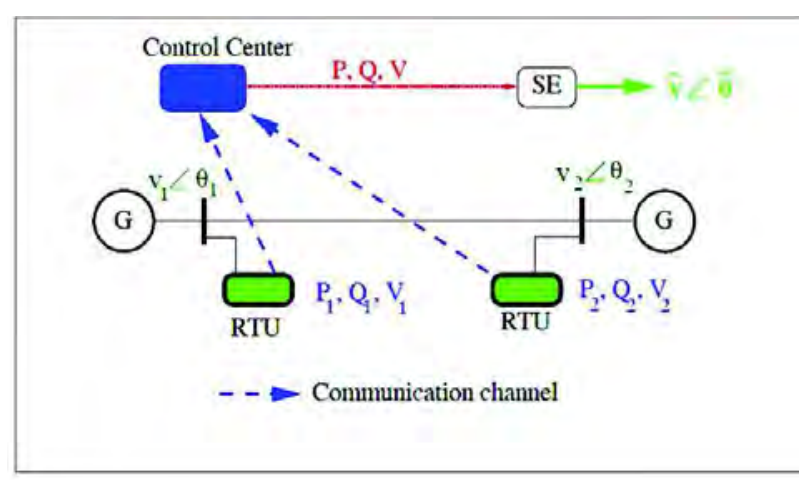

Fig. 7: Typical Conventional SCADA system

With the development of PMU-based Wide Area Monitoring System (WAMS), (Phadke and Thorpe, 2008), as shown in Fig. 8, which utilizes the timesynchronizing pulse (with an accuracy of one microsecond) from the Global Positioning System (GPS), it is possible to measure both the magnitude and the phasor angle of the bus voltages in the power systems. PMU typically provides phasor information once in one or two cycles. This fast refreshing rate 


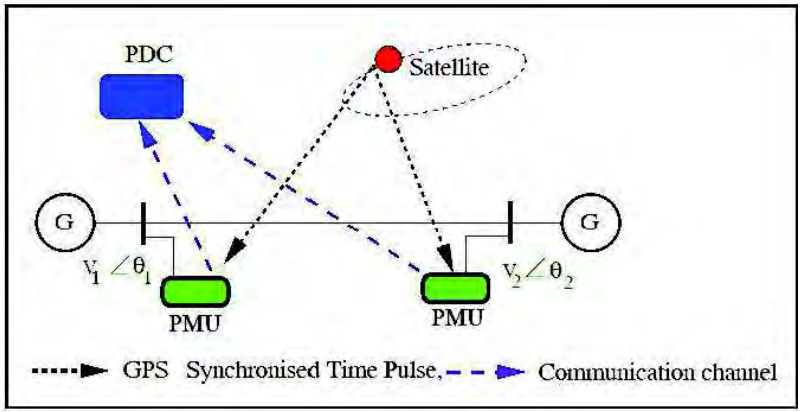

Fig. 8: Typical Wide Area Monitoring and Control System

of PMUs enables them to capture the system states during transient conditions. The data measured from the PMU are sent to Phasor Data Concentrator (PDC) by utilizing the wideband communication channels such as fibre optic channels. These measurements can further be utilized to take some fast control action, to ensure the stable operation of the power system.

Most of the utilities across the world are adopting Smart Grid technologies (Smart Grid report, DOE website; NIST report, 2012) to improve the overall operational and energy efficiency, customer satisfaction, security of the system and adopt greener technology. Some of the building blocks of smart grid are advance metering and communication, which includes smart meters, wide area monitoring system; substation and distribution automation along with distribution and operation management software; renewable integration; utility enterprise applications; and system integration. The smart grid will have distinct features such as self-healing to correct problems early; interactive with consumers and markets; optimized to make best use of resources; predictive to prevent emergencies; distributed assets and information; integrated merging all critical information; and more secure from threats from all system and external hazards.

At transmission level, synchrophasor technology based wide area monitoring and control system forms an important part of the smart grid. Its importance has been realized in understanding and analyzing the grid disturbance incidents in July 2012 (Report on grid disturbance in July 2012 in India), even with the data of only few PMU measurements deployed at pilot level.
Fig. 9 shows a typical block diagram of a PMU. The GPS receiver provides two signals, a periodic pulse train at a rate of one pulse per millisecond (1kPPS), and the Inter Range Instrumentation Group time code format B (IRIG-B) signal, which is a periodic pulse train at the rate of one time mark per second. The $1 \mathrm{kPPS}$ signal is utilized by the sampling clock to get synchronized with the GPS clock, whereas, the IRIG-B signal provides the time tag for the estimated phasors. The analogue voltage and current signals obtained from the secondary side of the potential and the current transformers, respectively, are preprocessed by an anti-aliasing filter to remove the presence of alias of the signals from the reconstructed signal. The analogue to digital converter samples the preprocessed analogue data, which are further utilized by the microprocessor-based phasor estimator.

The estimated phasors are finally sent to the PDC using the IEEE C37.118 data format (IEEE C37.118.1, 2011; IEEE C37.118.2, 2011). Synchrophasor technology based Wide-Area Monitoring, Protection, and Control System (WAMPCS) can be effectively utilized for systemwide monitoring, coordinated real time protection and control functions required to counteract the propagation of any major disturbances in the power system. PMU is one of the most vital elements of the WAMPC system. PMU reports time-tagged voltage and current phasors required for the dynamic monitoring functions at a much faster rate than the conventional Supervisory Control and Data Acquisition/Energy Management System (SCADA/ EMS). With relatively higher cost of PMUs as on

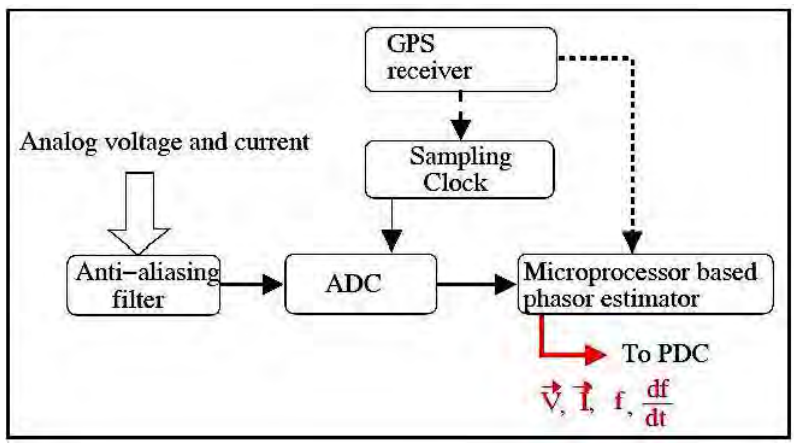

Fig. 9: Typical Block diagram of a PMU 
date, these have to be optimally placed to make the system observable (Sodhi et al., 2010a; Sodhi et al., 2011). Utilizing these dynamic measurements, the WAMPC system addresses the automated emergency control functions for various instabilities such as transient, frequency and voltage instabilities. As the conventional protective systems are decentralized and are non-adaptive in nature, a prerequisite for implementing the WAMPCS scheme is to make the protective relaying schemes adaptive. Various possible applications of the synchrophasorbased WAMPCS are as following.

- Phasor-assisted state estimation (Sodhi et al., 2010b)

- Dynamic phasor estimation (Banerjee and Srivastava, 2012)

- Machine rotor angle estimation using phasor measurements for transient stability prediction (Tripathy et al., 2010)

- WAMS-based critical mode identification for small signal stability assessment and control (Tripathy et al., 2011)

- Synchrophasor-based voltage stability assessment (Sodhi et al., 2012)

- Optimal frequency and voltage stability based load shedding (Seethalekshmi et al., 2011a)

- Wide area measurement based adaptive distance protection (Seethalekshmi et al., 2011b; Seethalekshmi et al., 2012)

- Model validation and wide area control (Padhy et al., 2012)

Some of the above analytics are being developed in-house for implementation in the URTDSM system in India.

\section{Role of Smart Grid Technology in Preventing Major Grid Disturbances}

In an integrated electricity grid, the power systems in different regions are interconnected and very often an incident initiated in one region may lead to a disturbance in other region also. Grid disturbance may result in a blackout, which refers to the total loss of power to an area and is the most severe form of the power outage that can occur. Outages may last from a few minutes to a few hours/days depending on the nature of the blackout, configuration of the electrical grid, system restoration time, etc. Some of the major blackout incidents across the world (as also listed in http://en.wikipedia.org/wiki/List_of_power_outages) are as following.

1965 US blackout on 9 November 1965 that affected 30 million people.

1999 Southern Brazil blackout on 11 March 1999 that affected 97 million people.

2003 Northeast blackout in the US and Canada on 14-15 August 2003 that affected 55 million people.

- 2003 Italy blackout on 28 September 2003 that affected 55 million people in Italy, Switzerland, Austria, Slovenia and Croatia.

- 2005 Java-Bali blackout on 18 August 2005 that affected 100 million people.

- 2009 Brazil and Paraguay blackout on 10-11 November, 2009, that affected 87 million people.

2012 Indian blackout on 30-31 July 2012 that affected 670 million people.

The Indian blackout on 30 and 31 July 2012 is considered to be the most severe in terms of the number of people affected. It caused the loss of power supply for about $14 \mathrm{~h}$ in North India on 30 July 2012 and for about 5-8 $\mathrm{h}$ the in northern, eastern and northeastern regions of the country on 31 July 2012 . These incidents resulted in a loss of a total load of 36,000 MW on 30 July and 48,000 MW on 31 July respectively, as given in the enquiry committee report (Report on grid disturbance in July 2012 in India). These incidents not only paralyse the life of people affected by the blackout, but also result in huge loss of revenue.

Most of the grid disturbances have been initiated under heavy system loading condition, triggered by the outage of critical line(s), due to natural calamity 
or faults, and lack of information and control. Some of the major causes observed in various incidents across the world include lack of situational awareness and real time monitoring tools, inadequate early security assessment/warning system, unintended operation of the protection/improper coordination of control actions, lack of enough reactive compensation, and human error \& grid indiscipline.

Continuous large capacity addition and expansion of the grid through increasing interconnections lead to increasing complexity in its management and operation. Open electricity market, wide variation in generation as well as demand on daily/seasonal basis, and increasing penetration level of renewable generation, etc. add to the complexity of the grid management. Maintaining safety, security and stability of such a large grid is posing greater challenges. Hence, it is important to know the dynamic state of the grid in real time to assess angular, voltage and frequency stability of the system; amount of increase in power transfer that can take place at different instances on various transmission elements; initiate control and regulation of power flow to maintain grid

\section{References}

Banerjee P and Srivastava S C (2012) A Subspace based Dynamic Phasor Estimator for Synchrophasor Application IEEE TransInstrum Meas 61 2436-2445

GonenT (2009) Electrical Power Transmission System Engineering: Analysis and Design, second ed. CRC Press

Hingorani N G and Gyugyi L (2000) Understanding FACTS: Concepts \& Technology of Flexible AC Transmission Systems. IEEE Press New York

IEEE Standard for Synchrophasor Data Transfer for Power Systems, C37.118.2-2011

IEEE Standard for Synchrophasor Measurements for Power Systems, C37.118.1-2011

Integrated Energy Policy (IEP), Planning Commission, Government of India, (August 2006), available at http:// planningcommission.gov.in/reports/genrep/rep_intengy. pdf

Monthly Power Sector Report of Central Electricity Authority, (March 2015), available at http://www.cea.nic.in/reports/ monthly/executive_rep/mar15.pdf under intact condition; and initiate Remedial Action Scheme(RAS) and System Integrated Protection Scheme (SIPS) in the event of severe contingency or likely condition, which may lead to grid disturbances, to take corrective actions.

The above aspects call for seamless integration of Intelligent/Smart Grid comprising WAMS using synchrophasor measurements provided by PMU at all substations in the grid integrated with high speed communication medium such as fibre optics, and powerful computing facilities at control centres, along with RAS, SIPS. This shall facilitate safety, security and reliability in operation of the large grid as well as ensure efficient utilization of transmission infrastructure. It also improves visualization, enhances situational awareness and controllability and ensures self-healing features. Smart grid implementation facilitates proper automation, information flow and data management, required for assessing the incipient system instability/insecurity condition and initiates emergency control actions to prevent system blackout.

National Electricity Plan Volume II Transmission (Feb 2012), available at http://www.cea.nic.in/reports/powersystems/ nep2012/transmission_12.pdf

National Power Training Institute website,http://www.npti.in/ Download/Transmission/ PRSTN_Transmission/ Powerline presentation on Power Transmission in India May2012/National Grid and High Capacity Corridors.pdf

Navani J P, Sharma N K and Sapra S (2012) Technical and NonTechnical Losses in Power System and its Economic Consequence in Indian Economy Int J Electron Comput Sci Eng 1 757-761

NIST Framework and Roadmap for Smart Grid Interoperability Standards (Feb 2012), Release 2.0, available at http:// www.nist.gov/smartgrid/upload/NIST_Framework_ Release_2-0_corr.pdf

Padhy B P, Srivastava S C and Verma N K (2012) Robust WideArea TS Fuzzy Output Feedback Controller for Enhancement of Stability in Multimachine Power System IEEE Syst $J 6$ 426-435

Perspective Transmission Plan for Twenty Years (2014-2034), (August 2014), http://www.cea.nic.in/reports/ powersystems/sppa/scm/allindia/notices/3rd_report.pdf 
Phadke A G and Thorpe J S (2008) Synchronized Phasor Measurements and Their Applications. Springer New York

POWERGRID Report on Green Energy Corridors: Transmission Plan for Envisaged Renewable Energy Capacity, (July 2012), available at http://www.powergridindia.com/ _layouts/PowerGrid/ WriteReadData/file/ourBusiness/ SmartGrid/Vol_1.pdf

POWERGRID website http://www.powergridindia.com

Report of the Enquiry Committee on Grid Disturbance in Northern region on (30 July, 2012) and in Northern, Eastern and North Eastern region on (31 July 2012), available at http://www.powermin.nic.in/pdf/GRID_ENQ_ REP_16_8_12.pdf

Report of The Working Group on Power for Twelfth Plan (201217), Ministry of Power, Government of India, (January 2012), available at http://planningcommission.nic.in/ aboutus/ committee/wrkgrp12/wg_power1904.pdf

Seethalekshmi K, Singh S N and Srivastava S C (2011a) A Synchrophasor Assisted Frequency and Voltage Stability Based Load Shedding scheme for Self Healing of Power System IEEE Trans Smart Grid 2 221-230

Seethalekshmi K, Singh S N and Srivastava S C (2011b) Synchrophasor Assisted Adaptive Reach Setting of Distance Relays in Presence of UPFC IEEE Syst J 5 396405

Seethalekshmi K, Singh S N and Srivastava S C (2012) A Classification Approach Using Support Vector Machines to Prevent Distance Relay Mal-operation under Power Swing and Voltage Instability IEEE Trans Power Delivery 27 1124-1133
Smart Grid: An Introduction, Report for the U.S. Department Of Energy (DOE) available at http://energy.gov/sites/prod/ files/oeprod/DocumentsandMedia/DOE_SG_Book_ Single_Pages(1).pdf

Sodhi R, Srivastava S C and Singh S N (2010a) Optimal PMU Placement Method for Complete Topological and Numerical Observability of Power System Electric Power System Res 80 1154-1159

Sodhi R, Srivastava S C and Singh S N (2010b) A Phasor Assisted Hybrid State Estimator Electr Power Compon Sys 38 533544

Sodhi R, Srivastava S C and Singh S N (2011) Multi-criteria Decision-making Approach for Multistage Optimal Placement of Phasor Measurement Units IET Gener Transm Dis 5 181-190

Sodhi R, Srivastava S C and Singh S N (2012) A Simple Scheme for Wide Area Detection of Impending Voltage Instability IEEE Trans Smart Grid 3 818-827

Talukdar S N and Wu F F (1981) Computer-aided Dispatch for Electric Power Systems PIEEE 69 1212-1231

Tripathy P, Srivastava S C and Singh S N (2010) A Divide-byDifference Filter Based Algorithm for Estimation of Generator Rotor Angle utilizing Synchrophasor Measurements IEEE Trans Instrum Meas 59 1562-1570

Tripathy P, Srivastava S C and Singh S N (2011) A Modified TLS-ESPRIT based Method for Low Frequency Mode Identification in Power Systems utilizing Synchrophasor Measurements IEEE Trans Power Syst 26 719-727

Wu F F, Moslehi K and Bose A (2005) Power System Control Centers: Past, Present and Future PIEEE 93 1890-1908 